\title{
A REVIEW: MOLECULAR REGULATION OF STOMATAL DEVELOPMENT RELATED TO ENVIRONMENTAL FACTORS AND HORMONES IN PLANTS
}

\author{
GUO, Z. F. ${ }^{1}-$ ZHAN, L. ${ }^{1}-$ ZHANG, Y. $^{1}-$ LI, J. J. ${ }^{1}-$ ZHAO, M. H. ${ }^{2}-$ XU, Z. J. ${ }^{2 *}-$ LI, M. M. ${ }^{3 *}$ \\ ${ }^{1}$ Key Laboratory of Agricultural Biotechnology of Liaoning Province, College of Biosciences \\ and Biotechnology, Shenyang Agricultural University, Shenyang 110866, China \\ ${ }^{2}$ Rice Research Institute, College of Agronomy, Shenyang Agricultural University, Shenyang \\ 110866, China \\ ${ }^{3}$ Rice Research Institute, Jiangxi Academy of Agricultural Sciences, Nanchang 330200, China \\ *Corresponding authors \\ e-mail/phonelfax: xuzhengjin@126.com,+86-24-8848-7183; Imm3056@163.com,+86-791-
} $8709-0751$

(Received 27 $7^{\text {th }}$ Apr 2019; accepted $11^{\text {th }}$ Jul 2019)

\begin{abstract}
Plants regulate leaf transpiration rate and water potential by changing the number of stomata and their rate of opening and closing. Stomata act as turgor-operated valves for gas exchange and water evaporation based on environmental needs. During stomatal development, various transcription factors and related genes are involved in the reception or transduction of environmental factors and hormones. Recent studies have led to significant advances in our understanding of intercellular signaling, the underlying pathways, and the polarity of the asymmetric division that controls stomatal development. The endogenous and exogenous factors that regulate these elements have also been identified. However, the mechanism of stomatal formation and development is highly complex and several morphogenesis-related questions are still unresolved. In this review, the molecular basis of stomatal development, including transcription factors, functional genes, and regulatory pathways, is described in detail. The connection between stomatal development and environmental factors such as $\mathrm{CO}_{2}$, light, temperature and air humidity is discussed. In addition, the influences of plant hormones on stomatal development are sketched out in the review. We also highlight critical questions requiring future research and form a detailed list involving in gene functions and trait changes in mutants.
\end{abstract}

Keywords: stomata, molecular mechanism, epidermal patterning factors, bHLH transcription factors, leucine-rich repeat receptor-like proteins

\section{Introduction}

Stomata are apertures typically observed on plant outer leaf layers; they maintain the optimal balance between $\mathrm{CO}_{2}$ uptake and water loss as a way to adapt environmental conditions in plants $(\mathrm{Ni}, 2012)$. In primary leaves of Arabidopsis, stomatal formation involves three types of cells: meristemoid mother cells (MMCs), guard mother cells (GMCs), and meristemoids (Behzadi et al., 2014). A protodermal cell develops into a stoma via three rounds of unequal cell divisions. First, the epidermal cell differentiates into a MMC through a series of unknown steps. The MMC then undergoes an asymmetric division to produce a small meristemoid cell and a stomatal-lineage ground cell (SLGC). The GMC develops into two GCs that flank a central pore to constitute a stoma (Bergmann and Sack, 2007). In addition, a SLGC can form satellite meristemoids (SMs) by spacing asymmetric division, with the SMs gradually differentiating into stomata. Most stomata are formed from SMs in this fashion. In addition to their balancing function, stomata play a significant role in water, carbon, and nutrient cycles. 
Thorough investigation of stomatal regulation is therefore essential for understanding plant physiological responses to the environment and their physical functions (Von et al., 2002).

The traditional model explains stomatal development and distribution in terms of cell developmental lineages, cell-cell interactions, and long-distance signaling. In monocotyledons, stomata are arranged in chains parallel to leaf veins (Geisler et al., 2000). In Arabidopsis and other dicotyledons, however, stomatal distribution on the leaf surface is irregular and individual stomata are spaced from one another (Serna and Fenoll, 2000). Although in-depth examinations would be beneficial to understand gas exchange and to reduce moisture loss, such investigations can be very difficult because of this stomatal variation and the complex relationship between stomatal development and the environment.

Many studies have recently shown that stomatal development is a tightly controlled process. The various transcription factors, secreted protein, protease and some regulatory pathways have been shown to play an important role. While several environmental and hormonal factors are known to affect stomatal development, very little is known about the molecular mechanism for these changes. In this review, we describe stomatal distribution patterns and formation, signaling pathways, and genes related to stomatal development accordingly, and discuss directions for future research. We also form a detailed list involved in genes function and trait changes in mutants (Table 1).

Table 1. Genes with mutations known to affect stomatal development in plant

\begin{tabular}{|c|c|c|c|c|}
\hline Locus & Symbol & $\begin{array}{c}\text { Mutant phenotype (or } \\
\text { overexpression phenotype) }\end{array}$ & Identity & References \\
\hline $\begin{array}{c}\text { EPIDERMAL PATTERNING } \\
\text { FACTOR } 1\end{array}$ & EPF1 & Increase stomatal densities & $\begin{array}{l}\text { Cysteine-rich secreted } \\
\text { peptide }\end{array}$ & Hara et al., 2009 \\
\hline $\begin{array}{c}\text { EPIDERMAL PATTERNING } \\
\text { FACTOR } 2 \\
\end{array}$ & EPF2 & Increase the number of MMCs & $\begin{array}{c}\text { Cysteine-rich secreted } \\
\text { peptide }\end{array}$ & Hara et al., 2009 \\
\hline STOMAGEN & STOMAGEN & Reduce stomatal density & $\begin{array}{c}\text { Cysteine-rich secreted } \\
\text { peptide }\end{array}$ & Sugano et al., 2010 \\
\hline CHAL-LAH/EPFL6 & CHAL & Increase stomatal density & $\begin{array}{c}\text { Cysteine-rich secreted } \\
\text { peptide }\end{array}$ & $\begin{array}{c}\text { Abrash and } \\
\text { Bergmann, } 2010\end{array}$ \\
\hline Too Many Mouths & TMM & $\begin{array}{c}\text { Stomatal clusters in leaves and } \\
\text { no stomata in stems }\end{array}$ & $\begin{array}{l}\text { Leucine-rich repeat } \\
\text { receptor }\end{array}$ & Geisler et al., 2000 \\
\hline $\begin{array}{l}\text { STOMATAL DENSITY AND } \\
\text { DISTRIBUTION }\end{array}$ & SDD1 & $\begin{array}{l}\text { Higher stomatal density and } \\
\text { some clusters }\end{array}$ & $\begin{array}{l}\text { Subtilisin processing } \\
\text { protease }\end{array}$ & Von et al., 2002 \\
\hline SPEECHLESS & $\mathrm{SPCH}$ & Fails to form stomata & bHLH transcription factor & $\begin{array}{l}\text { MacAlister et al., } \\
2007\end{array}$ \\
\hline MUTE & MUTE & Fails to form stomata & bHLH transcription factor & Pillitteri et al., 2007 \\
\hline FAMA & FAMA & $\begin{array}{l}\text { Fail to progress into GCs and } \\
\text { instead continue dividing }\end{array}$ & bHLH transcription factor & $\begin{array}{l}\text { Ohashi-Ito and } \\
\text { Bergmann, } 2006\end{array}$ \\
\hline SCREAM/ICE1 & SCRM & Fails to form stomata & bHLH transcription factor & Kanaoka et al., 2008 \\
\hline SCREAM2 & SCRM2 & Fails to form stomata & bHLH transcription factor & Kanaoka et al., 2008 \\
\hline $\begin{array}{c}\text { PHYTOCHROME- } \\
\text { INTERACTING FACTOR } 4\end{array}$ & PIF4 & Fail to produce more stomata & bHLH transcription factor & Casson et al., 2009 \\
\hline FOUR LIPs & FLP & $\begin{array}{c}\text { Induce the formation of } \\
\text { clusters of four or more GCs }\end{array}$ & $\begin{array}{l}\text { R2R3 MYB transcription } \\
\text { factors }\end{array}$ & Lee et al., 2014 \\
\hline $\begin{array}{c}\text { CO2 RESPONSE SECRETED } \\
\text { PROTEASE }\end{array}$ & CRSP & $\begin{array}{l}\text { More stomata at the elevated } \\
\mathrm{CO} 2 \text { concentration }\end{array}$ & Extracellular protease & Engineer et al., 2014 \\
\hline High carbon dioxide & HIC & Increase stomatal density & $\begin{array}{c}\text { 3-keto acyl coenzyme A } \\
\text { synthase }\end{array}$ & Gray et al., 2000 \\
\hline Carbonic anhydrase 1,4 & CA1, CA4 & Increase stomatal density & Carbonic anhydrase & $\begin{array}{c}\text { Hu et al., 2010; } \\
\text { Engineer et al., } 2014\end{array}$ \\
\hline
\end{tabular}




\begin{tabular}{|c|c|c|c|c|}
\hline Locus & Symbol & $\begin{array}{c}\text { Mutant phenotype (or } \\
\text { overexpression phenotype) }\end{array}$ & Identity & References \\
\hline $\begin{array}{l}\text { RETINOBLASTOMA- } \\
\text { RELATED }\end{array}$ & RBR & $\begin{array}{l}\text { Promoting initial GC identity, } \\
\text { but unable to maintain } \\
\text { commitment }\end{array}$ & $\begin{array}{l}\text { Similar to a human } \\
\text { protein called } \\
\text { Retinoblastoma }\end{array}$ & Matos et al., 2014 \\
\hline $\begin{array}{c}\text { CONSTITUTIVE } \\
\text { PHOTOMORPHOGENIC } 1\end{array}$ & COP1 & Producing stomatal clusters & Ubiquitin Ligase & Liu et al., 2008 \\
\hline $\begin{array}{c}\text { CONSTITUTIVE } \\
\text { PHOTOMORPHOGENIC } 10\end{array}$ & COP10 & Producing stomatal clusters & Ubiquitin Ligase & Delgado et al., 2012 \\
\hline Phytochrome B & phyB & Fail to produce more stomata & Red light photoreceptor & Casson et al., 2009 \\
\hline YODA MAPK(kk) & YDA & Fails to form stomata & $\begin{array}{c}\text { Mitogen activated protein } \\
\text { kinase }\end{array}$ & Lampard et al., 2009 \\
\hline BRI SUPPRESSOR1 & BSU1 & Massive stomata formation & Phosphatase & Kim et al., 2012 \\
\hline Cytochrome & CYP707A1 & $\begin{array}{c}\text { Prevent stomatal closure at } \\
\text { high } \mathrm{RH} \text { (Overexpression } \\
\text { phenotype) }\end{array}$ & ABA catabolism protein & $\begin{array}{l}\text { Arve et al., 2015; } \\
\text { Jalakas et al., } 2018\end{array}$ \\
\hline $\begin{array}{l}\text { BRI1-ASSOCIATED } \\
\text { RECEPTOR KINASE } 1\end{array}$ & BAK1 & $\begin{array}{c}\text { ABA insensitivity in stomatal } \\
\text { closure }\end{array}$ & $\begin{array}{l}\text { BRASSINOSTEROID- } \\
\text { INSENSITIVE } 1 \\
\text { ASSOCIATED } \\
\text { RECEPTOR KINASE } \\
\end{array}$ & Shang et al., 2016 \\
\hline ANGUSTIFOLIA3 & AN3 & $\begin{array}{c}\text { Decreased stomatal index } \\
\text { (loss-of-function) clusters of } \\
\text { stomata (overexpression } \\
\text { phenotype) }\end{array}$ & $\begin{array}{l}\text { Homolog of the human } \\
\text { transcription co-activator }\end{array}$ & Meng et al., 2018 \\
\hline $\begin{array}{l}\text { CONVERGENCE OF BL AND } \\
\text { CO2 } 1 / 2\end{array}$ & $\mathrm{CBC} 1 / 2$ & $\begin{array}{c}\text { Stomata in leaves closed } \\
\text { tighter }\end{array}$ & $\begin{array}{c}\text { Mitogen-activated protein } \\
\text { kinase kinase kinase }\end{array}$ & Hiyama et al., 2017 \\
\hline $\begin{array}{l}\text { BLUE LIGHT-DEPENDENT H+- } \\
\text { ATPASE PHOSPHORYLATION }\end{array}$ & BHP & $\begin{array}{c}\text { Impairments of stomatal } \\
\text { opening and H+-ATPase } \\
\text { phosphorylation in response to } \\
\text { blue light }\end{array}$ & Raf-like protein kinase & Hayashi et al., 2017 \\
\hline $\begin{array}{l}\text { ABA-INSENSITIVE PROTEIN } \\
\text { KINASE1 }\end{array}$ & AIK1 & $\begin{array}{c}\text { Stomatal closing is less } \\
\text { sensitive to ABA; slightly } \\
\text { greater stomatal density and } \\
\text { significantly increased } \\
\text { stomatal index }\end{array}$ & MAPKKK20 & Li et al., 2017 \\
\hline MPK12 & MPK12 & $\begin{array}{l}\text { Stomatal } \mathrm{CO}_{2} \text {-insensitivity } \\
\text { phenotypes of a mutant cis } \\
\left(\mathrm{CO}_{2} \text {-insensitive }\right) \text { and the } \\
\text { higher degree of stomatal } \\
\text { opening }\end{array}$ & MAP kinase & Jakobson et al., 2016 \\
\hline $\begin{array}{c}\text { SLOW ANION CHANNEL- } \\
\text { ASSOCIATED } 1\end{array}$ & SLAC1 & $\begin{array}{l}\text { Dramatically impair stomatal } \\
\text { closure induced by } \mathrm{CO}_{2}\end{array}$ & $\begin{array}{l}\text { S-type anion channel } \\
\text { protein }\end{array}$ & Vahisalu et al., 2008 \\
\hline $\mathrm{H}^{+}$-ATPase translocation control 1 & PATROL1 & $\begin{array}{l}\text { Impair stomatal opening in } \\
\text { response to low } \mathrm{CO}_{2} \\
\text { concentration and light }\end{array}$ & $\begin{array}{l}\text { Protein with a MUN } \\
\text { domain }\end{array}$ & $\begin{array}{c}\text { Hashimoto-Sugimoto } \\
\text { et al., 2013; Engineer } \\
\text { et al., } 2016\end{array}$ \\
\hline HIGH LEAF TEMPERATURE 1 & HT1 & $\begin{array}{c}\text { Constitutively open stomata } \\
\text { and impaired stomatal } \mathrm{CO}_{2} \\
\text { responses }\end{array}$ & Protein kinase & Jakobson et al., 2016 \\
\hline Open Stomata 1 & OST1 & $\begin{array}{c}\text { Insensitivity to } \mathrm{ABA} \\
\text { promotion of stomatal closure } \\
\text { and ABA inhibition of } \\
\text { stomatal opening }\end{array}$ & Protein kinase & Mustilli et al., 2002 \\
\hline ABA INSENSITIVE $1 / 2$ & $\begin{array}{l}\mathrm{ABI} 1 \text { and } \\
\mathrm{ABI} 2\end{array}$ & $\begin{array}{l}\text { ABA-induced stomatal } \\
\text { closing is abolished }\end{array}$ & Protein phosphatase $2 \mathrm{C}$ & Hirayama et al., 2007 \\
\hline BIG/CIS1 & BIG/CIS1 & $\begin{array}{l}\text { Fail to show reductions in } \\
\text { stomatal density and index, } \\
\text { but display inhibition of } \\
\text { stomatal opening with } \mathrm{eCO}_{2} \\
\text { concentration }\end{array}$ & Calossin-like protein & He et al., 2018 \\
\hline $\begin{array}{l}\text { BLUE LIGHT-DEPENDENT H+- } \\
\text { ATPASE PHOSPHORYLATION }\end{array}$ & BHP & $\begin{array}{c}\text { Impairments of stomatal } \\
\text { opening }\end{array}$ & $\begin{array}{l}\text { Raf-like kinase subfamily } \\
\text { in the MAPKKK family }\end{array}$ & Hayashi et al., 2017 \\
\hline Phot 1 and phot 2 & $\begin{array}{l}\text { Phot } 1 \text { and } \\
\text { phot } 2\end{array}$ & $\begin{array}{c}\text { Blue light-dependent stomatal } \\
\text { opening and the } \mathrm{H}^{+} \text {-ATPase } \\
\text { activation were absent }\end{array}$ & $\begin{array}{l}\text { Light-activated receptor } \\
\text { kinases }\end{array}$ & Doi et al., 2004 \\
\hline
\end{tabular}




\begin{tabular}{|c|c|c|c|c|}
\hline Locus & Symbol & $\begin{array}{c}\text { Mutant phenotype (or } \\
\text { overexpression phenotype) }\end{array}$ & Identity & References \\
\hline $\begin{array}{l}\text { Rac-interactive binding motif- } \\
\text { containing protein } 7\end{array}$ & RIC7 & $\begin{array}{l}\text { Promoted light-induced } \\
\text { stomatal opening }\end{array}$ & $\begin{array}{l}\text { Rac-interactive binding } \\
\text { motif-containing protein }\end{array}$ & Hong et al., 2016 \\
\hline $\begin{array}{l}\text { ENHANCED RESPONSE TO } \\
\text { ABA } 1\end{array}$ & ERA1 & $\begin{array}{c}\text { More closed stomata } \\
\text { phenotype; stomatal opening } \\
\text { induced by blue light was } \\
\text { impaired } \\
\end{array}$ & $\begin{array}{c}\text { Farnesyl transferase beta } \\
\text { subunit }\end{array}$ & Jalakas et al., 2017 \\
\hline Photosystem II Subunit S & PsbS & $\begin{array}{l}\text { Less stomatal opening in } \\
\text { response to light (over- } \\
\text { expression) }\end{array}$ & $\begin{array}{l}\text { Integral membrane } \\
\text { protein }\end{array}$ & Głowacka et al., 2018 \\
\hline $\begin{array}{l}\text { RESPIRATORY BURST } \\
\text { OXIDASE } 1\end{array}$ & RBOH1 & $\begin{array}{c}\text { Impaired } \mathrm{eCO}_{2} \text {-induced } \\
\text { stomatal closure and the } \\
\text { compromised eCO } \mathrm{eO}_{2} \text {-enhanced } \\
\text { water use efficiency as well as } \\
\text { the heat tolerance }\end{array}$ & $\begin{array}{c}\text { RESPIRATORY BURST } \\
\text { OXIDASE }\end{array}$ & Zhang et al., 2018 \\
\hline JASMONATE ZIM DOMAIN 2 & JAZ 2 & $\begin{array}{l}\text { Impaired pathogen-induced } \\
\text { stomatal closing }\end{array}$ & $\begin{array}{c}\text { JASMONATE ZIM } \\
\text { DOMAIN (JAZ) proteins }\end{array}$ & $\begin{array}{c}\text { Gimenez-Ibanez et } \\
\text { al., } 2017\end{array}$ \\
\hline MORE AXILLARY GROWTH 2 & MAX2 & $\begin{array}{c}\text { More widely opening stomata } \\
\text { or increased stomatal } \\
\text { conductance }\end{array}$ & $\begin{array}{l}\text { MORE AXILLARY } \\
\text { GROWTH protein }\end{array}$ & Piisilä et al., 2015 \\
\hline
\end{tabular}

\section{Basic signal transduction and molecular regulation}

Various transcription factors and other proteins involved in stomatal development have been studied along with their related genes. The encoded proteins include a family of epidermal patterning factors (EPFs), subtilisin-type proteinases (stomatal distribution and density 1 [SDD1]), leucine-rich repeat receptor-like proteins (TOO MANY MOUTHS [TMM]), basic helix-loop-helix (bHLH) transcription factors, and MAPK phosphatases (Geisler et al., 2000; Von et al., 2002; Hara et al., 2009; Jakobson et al., 2016). These studies, to some extent, have expounded the mechanisms of stomatal formation and development.

\section{Role of EPF}

$E P F$ genes encode a protein family of cysteine-rich peptides that include 11 member ligands in Arabidopsis. The EPF family peptides are classified into four subgroups based on their amino acid sequences. Some proteins have been identified as involved in stomatal development, such as epidermal patterning factor 1 (EPF1), epidermal patterning factor 2 (EPF2), STOMAGEN/EPFL9, and CHAL etc. (Hara et al., 2009; Abrash and Bergmann, 2010; Sugano et al., 2010).

\section{EPF1 and EPF2}

EPF1 and EPF2 affect the formation of stomatal precursors through distinct yet overlapping functions. Asymmetric cell division and the formation of stomatal clusters or pairs is controlled by EPF1, which is produced in meristemoids, GMCs, and GCs. Mature leaves lacking EPF1 consequently show an increase in the number of stomata and frequent stomatal pairing. EPF2 inhibits meristemoid formation and promotes the formation of pavement cells. The epf 2 mutant increases stomatal densities and leads to the formation of small, arrested stomatal lineage cells. In contrast, ectopic expression of EPF2 suppresses entry divisions, which leads to an epidermis composed only of pavement cells. The double mutant epfl/epf2 displays additive effects, causing greatly increased stomatal densities, stomatal pairing, and arrested cells (Hara et al., 2009; Hunt 
and Gray, 2009). Over-expression of either EPF1 or EPF2 has been found to suppress stomatal formation, but has revealed that they act on different developmental processes. EPF1 enforces the one-cell spacing rule, whereas EPF2 inhibits the population of cells from acquiring the stomatal lineage fate. $E P F 2$ can partly substitute for $E P F 1$ in function, but $E P F 2$ cannot be replaced by $E P F 1$. In addition, $E P F 2$ expression requires the bHLH transcription factor SPEECHLESS $(\mathrm{SPCH})$ and a MAPK (YODA [YDA]), suggesting that EPF2 is mediated by the MAPK cascade (Hara et al., 2009). EPF1 and its primary receptor ERECTA-LIKE1 (ERL1) target MUTE as a bHLH protein that controls the transition from meristemoids to GMCs and specifies the proliferation-todifferentiation switch within the stomatal cell lineages, while MUTE directly induces ERL1 (Du et al., 2018).

Although the function of EPF1 and EPF2 has been studied deeply in many aspects. Compared with EPF1, however, the function of EPF2 still remains some unknown domains that need to study further in the future. For example, how do the EPF2 peptide and ERECTA receptor affect the downstream signaling components? What proteases activate EPF2?

\section{STOMAGEN/EPFL9}

STOMAGEN/EPFL9 is an EPF known to positively influence stomatal development (Von et al., 2002). Over-expression of EPFL9 shows increased stomatal density and clustering, while loss of EPFL9 function leads to reduced stomatal density with no clustering. EPFL9 acts independently of EPF to regulate stomatal density and control stomatal clustering, while acts independently of $S D D$ to control both stomatal density and clustering (Hunt et al., 2010). In another study, it was showed that STOMAGEN controls stomatal development by binding with the TMM receptor protein to compete with EPF1 and EPF2. Genetic analysis has revealed that TMM is epistatic to STOMAGEN, which suggests that stomatal development is mediated by competitive binding of positive and negative regulators to the same receptor. Loss of STOMAGEN function results in fewer stomata. Conversely, STOMAGEN over-expression increases stomatal cluster formation and stomatal density (Hunt and Gray, 2009).

Even though the placement of stomata relative to one another has been demonstrated to be controlled by intercellular signaling via several EPFs, the extracellular proteases that function in EPFs pathways still remain unknown (Lee et al., 2015). Environmental signals that regulate the stomatal development via the extracellular propeptides EPFs or the protease SDD1 have still not been certified. Fortunately, the mechanism underlying the interaction of $\beta$-carbonic anhydrase and $\mathrm{CO}_{2}$ RESPONSE SECRETED PROTEASE (CRSP) that influences the action of EPF2 in the $\mathrm{CO}_{2}$ signaling pathway for stomatal development has been recently uncovered (Engineer et al., 2014). The elucidation of the detailed functions of EPFs other than EPF2 and their impacts on extracellular proteases and environmental signaling during stomatal development obviously requires further investigation.

\section{CHAL}

Similar to EPF1 and EPF2, CHAL inhibits stomatal formation. CHAL was studied during a screening designed to detect suppressors of tmm mutant, and only presented a phenotype in the presence of the tmm mutation. Although excess stomata were observed on leaf surfaces of tmm mutants, stomata were completely absent from stems. 
Interestingly, stomata reappeared on stems when CHAL was knocked out in the tmm mutant. Over-expression of CHAL requires ERECTA family (ERf) to suppress stomatal development. These differing results indicate that TMM may play a buffering role in the ERf receptor system, preventing EPF1 and EPF2 from disturbing the formation of normal epidermal patterns by absorbing excess CHAL (Abrash and Bergmann, 2010).

\section{Role of TMM}

TMM, a LRR-RLP receptor protein, negatively regulates stomatal density and placement. STOMAGEN positively regulates stomatal development, while EPF1 and EPF2 negatively regulate stomatal development by interacting with TMM as ligands. Loss of $T M M$ function fails to orient and suppress asymmetric divisions of cells adjacent stomata or their precursors; in addition, loss-of-function mutants undergo a reduced number of divisions, resulting in the premature conversion of meristemoids into GMCs (Geisler et al., 2000). TMM plays an important role in cell-cell communication and perceives information regarding transient contiguous cell confirmation and location (Bergmann and Sack, 2007). The secretory peptides encoded by EPFs are expressed in meristemoids, with their activity dependent on the function of TMM and ERf members. ERfs and TMM work cooperatively to inhibit stomatal production. EPFs require TMM or ERfs to certify their over-expression phenotypes, which indicates the importance of these three proteins in EPf perception (Horst et al., 2015; de Marcos et al., 2016).

\section{Role of SDD}

SDD1 is a negative regulator of stomatal development, which encodes a subtilisin-like serine protease. SDD1 affects both protoderm and neighboring cell fates. During the development of neighboring cells, the shift from pavement cells to SM precursors may be controlled by a SDD1-dependent reaction signal in meristemoids/GMCs. Whether the meristemoid/GMC response causes the neighboring cell shift or instead triggers or extends SDD1 expression is unclear (Von et al., 2002). Loss of SDD1 function leads to properly spaced but denser stomata. In one investigation, a 1.5-fold increase in stomatal density and index were reported in two sdd1-1 mutants of Arabidopsis (Bergmann and Sack, 2007). SDD1 overexpression causes a two- to four-fold decrease in stomatal density but does not considerably alter leaf and epidermal cell sizes (Von et al., 2002).

\section{Role of bHLH transcription factors}

In plants, bHLH transcription factors constitute an evolutionarily ancient group known to specify cellular identity. Some homologous bHLH proteins play important roles in the determination of the fate of successive stomatal precursor cells. For example, SPCH, MUTE, and FAMA act to activate cellular transition about stomatal development, share 88\% structural homology and 39\% sequence homology. Despite their similarities, they can not functionally replace each other during stomatal development because of the specific features of each protein (Ohashi-Ito and Bergmann, 2006).

\section{$\mathrm{SPCH}$}

The SPCH gene is the key factor in the process of protodermal cell division into MMCs. SPCH involves in a basic pathway that initiates asymmetric division in the stomatal lineage (MacAlister et al., 2007; Vatén et al., 2018). The spch mutant fails to 
produce interlocking pavement cells and promote stomatal lineages, while overexpression of SPCH raises the number of cells in the stomatal pathway. In addition, SPCH can prolong meristemoid identity, as loss of SPCH function leads to that meristemoids divide significantly fewer times. SPCH is also a target of brassinosteroid $(\mathrm{Br})$ and MAPK signaling, and is an integration point for environmental information that allows for appropriate patterning and optimization of stomatal density under changing conditions (Ohashi-Ito and Bergmann, 2006).

\section{MUTE}

MUTE is a bHLH protein that controls the transition from meristemoids to GMCs, which promotes the differentiation of meristemoids into stomata (Pillitteri et al., 2007; Mahoney et al., 2016). The mute mutant fails to form stomata, but has no effect on meristemoid formation. Over-expression of MUTE has been shown to shift all epidermal cells toward stomata. The promoter of MUTE is not active in meristemoids, but is specifically activated in late-stage meristemoids. It was suggested that MUTE promoters binding with one finger regulatory elements is important for regulation (Mahoney et al., 2016). Because it is difficult to predicate the number of meristemoid divisions, how meristemoids regulate the timing of MUTE expression and the end of meristemoid division is unclear.

\section{FAMA}

FAMA, which controls GC fate, is expressed during the symmetric division that produces the two young GCs, but not in mature stomata (Ohashi-Ito and Bergmann, 2006). This protein likely acts as a transcriptional activator to regulate the transition from GMCs to GCs during symmetric division. Loss of FAMA function results in lack of mature stomata, while it develops clusters of GMCs or incipient GCs. Overexpression of FAMA converts non-stomatal cells to GCs in fama mutant plants (OhashiIto and Bergmann, 2006). Matos et al. (2014) found that FAMA must bind to another protein, RETINOBLASTOMA-RELATED (RBR), to control the GMC to GC transition. These two proteins cause a permanent transition from stem cells to GCs. When the partnership between FAMA and RBR is broken, reversion of the GCs into stem cells can be observed.

\section{SCRM and SCRM2}

SCRM and SCRM2 are two additional bHLH proteins, which promote cellular transitions during stomatal development. Both of these proteins share high sequence homology and encode bHLH-type leucine zipper nucleoproteins. SCRM and SCRM2, which exist in cells of all stages, are similar in expression and function (Kanaoka et al., 2008). A scrm single mutant displays phenotypes similar to the fama mutant, while the scrm-scrm 2 double mutant produces occasional spch-like columns. It was showed that SCRM and SCRM2 interact with SPCH, MUTE, and FAMA. Map-based cloning has shown that SCRM is one of the key regulatory factors during cold stress, indicating that the ability of plants to adapt to environmental conditions may be related to developmental factors (Serna and Fenoll, 2000). Both environmental and developmental factors regulate stomatal development, which implicates SCRM as a participant in the integration of environmental signals directly into the stomatal differentiation pathway (Lee et al., 2017). 
Taken together, these three bHLH family members-SPCH, MUTE, and FAMAcontrol formation, amplification, division, and final differentiation in stomatal development (Fig. 1). Remarkably, the SPCH protein can be phosphorylated by MPK3 and MPK6, whereas no such phosphorylation has been reported for MUTE and FAMA. SPCH generates stem cells and triggers their asymmetric division, while MUTE controls the meristemoid-to-GMC transition. SPCH, MUTE, and FAMA form obligate heterodimers with ICE1/SCRM and SCRM2, but not among themselves. These genes non-redundantly and positively regulate the stomatal development. However, interaction with RBR is inadequate to define the feature of FAMA and indicate a version of FAMA that behaves like MUTE or SPCH (Davies and Bergmann, 2014). It is necessary to study the larger interacted complexes that contribute to stomatal lineage by further work on protein interactions. It is also needed to identify what kind motifs are involved in these protein interactions.

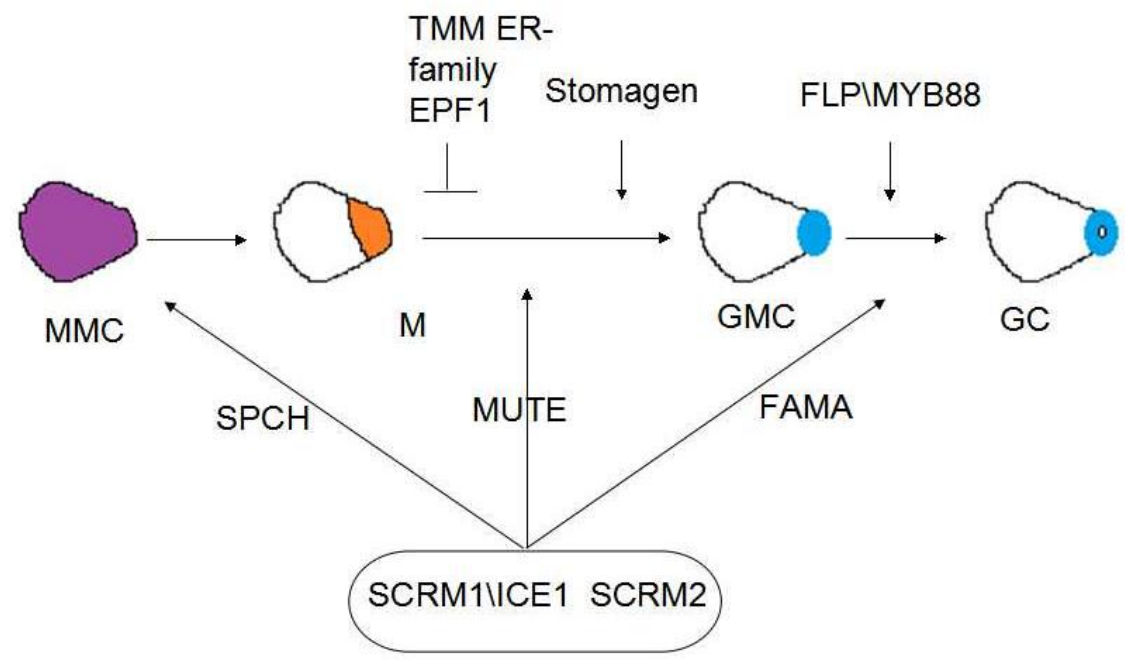

Figure 1. Model of the differentiation steps regulated by sequential actions of bHLH transcription factors and related genes. MMC: meristeoid mother cell (purple), M: meristemoid (orange), GMC: guard mother cell (blue), GC: guard cell (blue with circle)

\section{Role of MAPK cascades}

The MAPK signaling pathway controls cell fate and division during stomatal development. MAPK cascades are organized into a core module comprising three protein kinases: a MAPK, a MITOGEN-ACTIVATED PROTEIN (MAP) kinase kinase (MKK), and a MAP kinase kinase kinase (MAPKKK). YDA, a MAPKKK in the MAPK cascade, negatively regulates stomatal development. The associated signaling pathway consists of YDA, MKK4/5/7/9, and MPK3/6/9. The YDA-MKK4/5-MPK3/6 complex negatively regulates processes involved in the formation of GMCs from MMCs and of GCs from GMCs. YDA-MKK7/9, in contrast, positively controls these processes (Lampard et al., 2009). Loss of AtYDA function generates a clear increase in the production of leaf stomata in Arabidopsis, whereas expression of constitutively active mutants of AtYDA causes repressed stomatal formation in leaf epidermis. Furthermore, epidermal cells of $y d a$ mutant cotyledons display excessive entry divisions, thereby failing to prevent division of neighboring cells that connect two stomatal lineage cells. Asymmetry of cell fates is also compromised in $y d a$ mutants. 
Over-expression of $Y D A$ leads to a significant decrease in stomatal density and the rate of water loss (Bergmann and Sack, 2007). ABA-INSENSITIVE PROTEIN KINASE1 (AIK1) gene encodes MAPKKK20 and positively regulates ABA-induced stomatal closure. The stomatal closing in aikl mutants was less sensitive to ABA than that in wild-type plants. In addition, the aikl mutants exhibit slightly greater stomatal density and significantly increased stomatal index. It was revealed that MKK4 and MKK5 could interact with AIK1 in vivo (Li et al., 2017). As another MAPK cascade, MPK12 regulates the stomatal aperture. Loss of MPK12 function results in the stomatal $\mathrm{CO}_{2}$ insensitivity phenotypes and the higher degree of stomatal opening. It was showed that MPK12 interact with the protein kinase HIGH LEAF TEMPERATURE 1 (HT1) to inhibit the activity of HT1. Because of the higher degree of stomatal opening, the instantaneous water use efficiency is lower in mpk12 mutants, suggesting that MPK12 is a important regulator of stomatal conductance (Jakobson et al., 2016).

\section{The influence of environmental factors}

\section{Role of $\mathrm{CO}_{2}$ concentration}

In the plant epidermis, the adjustable stomatal pores formed by $\mathrm{GCs}$ allow $\mathrm{CO}_{2}$ to enter for photosynthesis and water from transpiration to escape to the atmosphere. Plants accommodate to a continuous rise in atmospheric $\mathrm{CO}_{2}$ concentration by adjusting stomatal density and closing stomata (Hu et al., 2015; Engineer et al., 2016). Gray et al. (2000) have identified a gene, designated as HIC (for high carbon dioxide), that is related to the signal transduction pathway responsible for regulating stomatal numbers at elevated $\mathrm{CO}_{2}\left(\mathrm{eCO}_{2}\right)$. $\mathrm{HIC}$ encodes a protein similar to 3-ketoacyl coenzyme $\mathrm{A}$ synthase, which is expressed specifically in GCs. Loss of $H I C$ function results in an increase in stomatal density for reacting to a doubling of $\mathrm{CO}_{2}$. HIC is the first gene to be identified that affects plant developmental responses to global changes in atmospheric composition. $\beta$-carbonic anhydrase $(\beta C A)$ is a $\mathrm{CO}_{2}$-binding protein that functions early in the $\mathrm{CO}_{2}$ signaling pathway for stomatal development. Two $\beta \mathrm{CAs}, \mathrm{CA} 1$ and CA4, were identified that function in the $\mathrm{CO}_{2}$ response. Double mutants (cal ca4) result in an inversion in response to $\mathrm{eCO}_{2}$ by increasing stomatal development (Hu et al., 2010). Over-expression of $C A 4$ and $C A 1$ could refresh $\mathrm{CO}_{2}$-induced stomatal responses in double mutants. The ca4 mutant shows a slightly altered sensitivity to the $\mathrm{CO}_{2}$ stimulus (Hu et al., 2015; Engineer et al., 2016).

A novel $\mathrm{CO}_{2}$-induced extracellular protease, CRSP, has been identified as a mediator of $\mathrm{CO}_{2}$ regulation of stomatal development during atmospheric $\mathrm{CO}_{2}$ elevation. Interaction of CA1, CA4, and CRSP degrades the pro-peptide EPF2, repressing stomatal development. However, EPF2 is vital to $\mathrm{CO}_{2}$ regulation of stomatal development (Engineer et al., 2014). Future research should focus on if feedback modulation results in $\mathrm{CO}_{2}$ regulation of EPF2 and CRSP transcripts and what are the transcriptional regulators regulating the $\mathrm{eCO}_{2}$ response. SLOW ANION CHANNELASSOCIATED 1 (SLAC1) is an S-type anion channel protein, which plays a important role in stomatal closure in response to $\mathrm{eCO}_{2}$. Loss of AtSLACl function dramatically represses stomatal closure induced by $\mathrm{CO}_{2}$ (Vahisalu et al., 2008; Hedrich and Geiger, 2017).

Stomatal opening is promoted by the activation of $\mathrm{H}^{+}$-ATPases (AHA1) in the guard cell plasma membrane, and $\mathrm{eCO}_{2}$ concentration inhibits proton efflux by plasma membrane AHA1 (Hashimoto-Sugimoto et al., 2013). The PATROL1 gene encodes a 
protein with a MUN domain, which is involved in the membrane trafficking of neurotransmitter release. Loss of PATROL1 function results in the impaired stomatal opening in response to low $\mathrm{CO}_{2}$ concentration, disturbing the normal plasma membrane targeting of $\mathrm{H}^{+}$-ATPases (Engineer et al., 2016).

HT1 is a protein kinase and an essential regulator of stomatal $\mathrm{CO}_{2}$ responses. Loss of HT1 function results in constitutively stomata opening and repressed stomatal $\mathrm{CO}_{2}$ responses (Jakobson et al., 2016). The open stomata 1 (OST1) protein kinase is involved in $\mathrm{CO}_{2-}$ and $\mathrm{ABA}$-induced stomatal closing (details in ABA section). It was suggested that HT1 phosphorylates the OST1 protein kinase, which inactivates OST1 (Mustilli et al., 2002; Tian et al., 2015). BIG/CIS1 is a calossin-like protein, which regulates $\mathrm{CO}_{2}$-induced stomatal closure (He et al., 2018). Loss of BIG/CIS1 function fails to show reductions in stomatal density and index, but displays inhibition of stomatal opening with $\mathrm{eCO}_{2}$ concentration. It was showed that BIG/CIS1 is only demanded in $\mathrm{eCO}_{2}$-induced stomatal closure, suggesting the signaling pathways of $\mathrm{CO}_{2}$ mediated promotion of stomatal closure are distinguishable with inhibition of opening (He et al., 2018). Because BIG/CIS1 is associated with auxin transport, further research should focus on if disruptions to auxin signaling underlie the BIG/CIS1 stomatal mutant phenotype. These studies could help researchers to choose plant germplasm for adapting to $\mathrm{CO}_{2}$ levels.

\section{Role of light}

Light intensity affects stomatal density and the stomatal index, which play an important role in cell fate decisions in the epidermis (Casson et al., 2009). CONSTITUTIVE PHOTOMORPHOGENIC 1 (COP1), a E3 ubiquitin-protein ligase, is a repressor of light-controlled stomatal development (Liu et al., 2008). A current study showed that COP1 degrades ICE through ubiquitination pathways in leaf abaxial epidermal cells. Loss of COP1 function results in the ICE proteins accumulate in the nuclei of leaf abaxial epidermal cells. Interestingly, light impairs the COP1-mediated degradation of the ICE to induce stomatal development, which upregulates EPF2 activity at the transcriptional level, thereby conferring proper stomatal spacing and distribution. Thus, it is likely that the COP1-ICE-EPF2 signaling module integrates light signals into developmental programs that regulate stomatal development (Lee and Park, 2017). ANGUSTIFOLIA3 (AN3) is a positive regulator of stomatal development, which interacts with the COP1 promoter to regulate light-induced stomatal development. Loss of AN3 function results in decreased stomatal index, whereas overexpression of $A N 3$ leads to clusters of stomata (Meng et al., 2018). These suggest that the AN3-COP1-E3 pathway regulates stomatal development with the integration of light signaling. COP10 is another dominant component of stomatal-lineage divisions, which represses stomatal fate and adjusts the initiation frequency and extension of stomatal lineages. Loss of COP10 function results in the production of stomatal clusters. COP10 regulates genetically in parallel with SDD1 and does not affect epidermal cell differentiation (Delgado et al., 2012). Phytochrome B (phyB) plays an important role in red light-induced stomatal development. Loss of $p h y B$ function prevents this increased production of stomata under high intensity red light. phyB can also promote the expression of FAMA and TMM genes in young leaves (Casson et al., 2009). Consequently, phyB has a significant role in the mediation of epidermal cell division and stomatal development. PHYTOCHROME-INTERACTING FACTOR 4 (PIF4), a bHLH transcription factor, can be transported to the nucleus upon binding to 
phyB. PIF4 may also regulate stomatal development with SPCH, MUTE, and FAMA. Mutations of PIF4 display a similar defect as in the absence of phyB (Casson et al., 2009).

Plasma membrane $\mathrm{H}^{+}$-ATPase regulates blue light-induced stomatal opening. It is activated via a signaling mediator BLUE LIGHT SIGNALING1 (BLUS1) and blue light-receptor phototropins (phot1 and phot2). BLUS1 and phosphatase act as positive mediators between the H+-ATPase and the phots during stomatal opening. BLUE LIGHT-DEPENDENT $\mathrm{H}^{+}$-ATPASE PHOSPHORYLATION (BHP) is a novel signaling regulator in blue light-induced stomatal opening interacting with BLUS1, which is owned by the MAPKKK family. Loss of BHP function results in impaired stomatal opening in response to blue light (Hayashi et al., 2017). The phots are lightinduced receptor kinases, which mediate stomatal opening and phototropism. the phot 1 phot 2 double mutant fails to show the blue light-induced stomatal opening and the $\mathrm{H}^{+}$ATPase activation, but phot 1 and phot 2 single mutants retain these responses (Doi et al., 2004). A recent study displayed that BLUS1 kinase is phosphorylated by phot1 and phot2, which acts as a common substrate in stomatal opening through the activation of the plasma membrane $\mathrm{H}^{+}$-ATPase via phosphatase (Takemiya and Shimazaki, 2016).

The light-induced stomatal opening is also inhibited by Rho-type (ROP) GTPase 2 (ROP2). ROP-interactive Cdc42- and Rac-interactive binding motif-containing protein 7 (RIC7) interacts ROP2 and mediates downstream processes. Loss of RIC7 function activates light-induced stomatal opening, while overexpression of RIC7 represses lightinduced stomatal opening. RIC7 interacts also with Exocyst subunit Exo70 family protein B1 (Exo70B1), a positive regulator of stomatal opening, to optimize the extent of stomatal opening by inhibiting the function of Exo70B1. The mutant exo70b1 and double mutant ric7/exo70b1 both display inhibited light-induced stomatal opening (Hong et al., 2016). ENHANCED RESPONSE TO ABA 1 (ERA1) encodes the farnesyl transferase $\beta$ subunit, which dominates stomatal closure in plants. Loss of ERA1 function results in more closed stomata phenotype. Further studies indicated that eral mutants shows impaired blue light-induced stomatal opening, which suggested a potential function for ERA1 farnesylation in blue light-induced stomatal opening (Jalakas et al., 2017). In addition, Photosystem II Subunit S (PsbS), a integral membrane protein, affects a chloroplastderived signal for light-induced stomatal opening. Over-expression of $P s b S$ results in impaired light-induced stomatal opening and a $25 \%$ reduction in water loss per $\mathrm{CO}_{2}$ assimilated under field conditions (Głowacka et al., 2018).

\section{Synergy effects of light and $\mathrm{CO}_{2}$}

The stomatal opening is mediated by light and low concentrations of $\mathrm{CO}_{2}$ with synergy effects. CONVERGENCE OF BLUE LIGHT AND CO2 1/2 (CBC1/CBC2) are protein kinases related to blue light, which redundantly promote stomatal opening in response to both blue light and low concentrations of $\mathrm{CO}_{2}$. It was suggested that $\mathrm{CBCs}$ positively mediate stomatal aperture by integrating signals from blue light and low $\mathrm{CO}_{2}$ (Hiyama et al., 2017). In contrast to blue light-induced stomatal opening, the viewpoints about red light-induced stomatal opening are controversial. Some studies showed that red light-induced stomatal opening may be resulted in a low intercellular concentration of $\mathrm{CO}_{2}$ brought about by mesophyll photosynthesis (Horrer et al., 2016) However, other investigators suggested that such a reduction in the intercellular concentration of $\mathrm{CO}_{2}$ of leaves was insufficient to lead to stomatal opening. Hiyama et al. (2017) speculated that 
the reduced intercellular concentration of $\mathrm{CO}_{2}$ might result in stomatal opening by inhibiting the S-type channels through CBCs, but such a response did not display in the $c b c$ mutants. Further study is needed to elucidate the role of CBCs in red light-induced stomatal opening.

\section{Temperature and air humidity}

Temperature affects stomatal development in a complex manner. Temperature increases often leads to somatal opening, whereas heat stress often promptly mediates stomatal closure to decrease transpirational water loss in some plant species (Lahr et al., 2015). Increased temperature restrains the expression of SPCH that acts as the major mediator of stomatal lineage initiation (Vatén et al., 2018). PIF4 is also a core component of high-temperature signaling, which accumulates in the stomatal precursors and combines with the promoter of SPCH in increased temperature. In addition, PIF4 represses also SPCH activation and stomatal production. This study proposed a model where warm-temperature-activated PIF4 binds and represses SPCH expression to restrict stomatal production at increased temperatures (Lau et al., 2018). The $\mathrm{CO}_{2-}$ induced variations of stomatal closure associates with heat stress tolerance. The $\mathrm{eCO}_{2}$ moderates the negative effects of heat stress, which is accompanied by greater amounts of RESPIRATORY BURST OXIDASE 1 (RBOH1) transcripts and decreased stomatal aperture. Loss of $\mathrm{RBOH} 1$ function results in the impaired $\mathrm{eCO}_{2}$-induced stomatal closure and the compromised $\mathrm{eCO}_{2}$-enhanced water use efficiency as well as the heat tolerance (Zhang et al., 2018).

Stomatal movement is influenced by relative air humidity $(\mathrm{RH})$ with ABA content. High elevated air movement (MOV) reduced length and aperture of stomata in plants developed at high RH and increased stomatal sensitivity to ABA (Carvalho et al., 2015). In this process, CYP707A1, a ABA catabolism gene, plays a prominent role for influencing stomata development and ABA content. Over-expression of CYP707A1 during dark in high $\mathrm{RH}$ reduced the ABA content in the guard cells and prevented stomatal closure, whereas loss of CYP707A1 gene function resulted in reduced stomatal aperture (Arve et al., 2015; Jalakas et al., 2018). Compared with the influence of $\mathrm{CO}_{2}$ and light on stomatal development, the molecular mechanisms underlying the action of temperature and air humidity on stomatal development should be further and deeper to study.

\section{The influence of plant hormones}

Some hormones, such as Abscisic acid (ABA), jasmonate (MeJA), Brassinosteroids (BRs), Strigolactones (SLs), Salicylic acid (SA) etc. have a strong correlation with stomatal development. With the mechanism of stomatal development being studied in the past decade, many researches have opened the door to understand the function of plant hormone in stomatal development.

\section{Role of $A B A$}

ABA is well known to mediate the opening and closing of stomata in response to changes in water balance. ABA levels are low in the Arabidopsis aba2 mutant, with the mutant displaying high stomatal density. ABA INSENSITIVE 1 and ABA INSENSITIVE 2 (ABI1 and $\mathrm{ABI} 2$ ) are protein phosphatase $2 \mathrm{C}$ proteins, which regulate 
ABA-mediated stomatal closure interacting with protein kinases OST1 (Tanaka et al., 2013). The pathway for ABA-mediated stomatal closure is related to perception of ABA that results in the activation of guard cell anion channels by OST1. Loss of OST1 function results in insensitivity to ABA-mediated stomatal closure and opening, which indicates that OST1 is a positive regulator in ABA signaling (Mustilli et al., 2002; Acharya et al., 2013). OST1 needs normal ABI1 function for its ABA-dependent activation and interacts directly with ABI1 protein (Park et al., 2009). In addition, ABAinduced stomatal closing are abolished in abil and abi2 mutants (Pei et al., 1997). Although ABA interacts with different functional proteins, transcription factors, kinases, and various environmental factors, the molecular mechanisms about these interaction are massively complex and are not entirely clear.

\section{Role of MeJA}

The exogenous MeJA can reduce the stomatal index and stomata density on the cotyledons of Arabidopsis. Coronatine (COR) is perceived via a receptor complex formed by CORONATINEINSENSITIVE 1 (COI1) and JASMONATE ZIM DOMAIN (JAZ) proteins, which promotes entry of bacteria into the plant apoplast by facilitating stomata opening (Yan et al., 2009). COR and jasmonate isoleucine (JA-Ile) co-receptor JAZ2 modulates stomatal aperture by the signaling module COI1-JAZ2-MYC2,3,4ANAC19,55,72 during bacterial invasion. The jaz2 mutant shows partially repressed pathogen-induced stomatal closing, which is more sensitive to Pseudomonas. The JAZ2 binds to the MYC transcription factors directly mediate the expression of ANAC19,55,72 to control stomata aperture (Gimenez-Ibanez et al., 2017). In addition, the MYC transcription factors negatively modulate jasmonate-inhibited stomatal development and act upstream of the SPCH and FAMA to regulate stomatal development. The stomatal development of the myc2 myc3 myc4 triple mutant is insensitive to MeJA treatment (Han et al., 2018).

\section{Role of BRs}

BRs are steroid hormone that promotes stomatal closure in an ABA-independent manner (Kim et al., 2012). BRASSINOSTEROID INSENSITIVE2(BIN2), a important regulator in BR signaling, encode a glycogen synthase kinase 3 (GSK3)-like kinase (He et al., 2002). BRs negatively modulate stomatal development by repressing BIN2 kinase-induced inhibition of YDA. BIN2 phosphorylates and inactivates the YDA, which inhibits stomata formation. Overexpression of BIN2 displays a similar stomatal overproduction phenotype as $b s u$ mutants. Besides, BRs have been directly involved in stimulating stomatal development in hypocotyls through BIN2 phosphorylation and inactivation of $\mathrm{SPCH}$, which acts downstream of the MAPKs and stimulates cell division and stomatal development. BRASSINOSTEROID-INSENSITIVE 1 (BRI1) kinase binding with BR recruits BRI1-ASSOCIATED RECEPTOR KINASE 1 (BAK1) to produce a receptor complex on plasma membranes (Shang et al., 2016). Transphosphorylation between BRI1 and BAK1 further enlarges BRI1 and BAK1 kinase activities, which results in inactivation of BIN2 by the upstream phosphatase BRI SUPPRESSOR1(BSU1) under high BR levels (Zhu et al., 2013). Loss of BSU1 function results in massive stomata formation, which needs BIN2 activity (Kim et al., 2012). Loss of $B A K 1$ function results in insensitivity of ABA-mediated stomatal closure and inhibition of OST1 expression and ROS production. It was further indicated that 
BAK1 interacts with OST1 near the plasma membrane, which increases sensitivity in response to ABA. In addition, ABI1 interacts with BAK1 and impairs the interaction of BAK1 and OST1 (Shang et al., 2016).

\section{Role of SLS}

SLs play a vital role in regulating stomatal closure in an ABA-independent mechanism. SLs promotes a significant increase in $\mathrm{H}_{2} \mathrm{O}_{2}$ and $\mathrm{NO}$ contents, which is needed for stomatal closure. Disruption of MORE AXILLARY GROWTH 2 (MAX2), DWARF14 (D14), and SLAC1 represses SL-induced stomatal closure. Loss of MAX2 function leads to increased stomatal conductance and more widely opening stomata (Piisilä et al., 2015). The slacl mutant shows compromised SL-mediated stomatal closure, showing that SLAC1 is necessary for SL-mediated stomatal closure. Although SL-induced stomatal closure requires $\mathrm{H}_{2} \mathrm{O}_{2}$, NO, and SLAC1, the detailed molecular mechanism by if SLs regulate the stomatal response remains unknown. It will be required to study whether $\mathrm{H}_{2} \mathrm{O}_{2}$-activated $\mathrm{Ca}^{2+}$ channels are also needed for SL-induced stomatal closure (Lv et al., 2018).

\section{Role of $S A$}

SA regulates ROS production in guard cells through peroxidase-catalyzed reaction, leading to stomatal closure. AtSIZ1 is a small ubiquitin-like modifier (SUMO) E3 ligase, which negatively mediates stomatal apertures via the SA-triggered ROS accumulation. Loss of AtSIZ1 function leads to the accumulation of endogenous SA, which enhances the production of ROS mediated by salicylhydroxamic acid (SHAM)sensitive peroxidases and impairs stomatal aperture (Miura et al., 2013). In addition, plants growing in the ethylene precursor 1-aminocyclopropane-1-carboxylic acid display increased stomatal density. Stomatal division and development is enhanced in cucumber hypocotyls after brief treatment with ethylene. Furthermore, auxin and gibberellin modulate stomatal aperture opening and closing (Saibo et al., 2003). Compared with other molecular regulatory pathways, the molecular mechanisms underlying the action of $\mathrm{ABA}$ and other hormones on stomatal development have not been clearly established.

\section{Future directions}

Stomata enable plants to regulate the entry of $\mathrm{CO}_{2}$ assimilated in photosynthesis and adjust evaporation of water. Although some underlying mechanisms and genes related to stomatal development have been studied, many complex questions related to stomatal morphogenesis and division are still largely unanswered. Future research should involve bioinformatics mining of published gene data, information analysis of transcriptomic and proteomic for deeply studying stomatal development and guard cell responses to environmental factors. In addition, very little is known about the underlying molecular basis for the changes of hormonal factors such as ABA, ethylene, auxin, and gibberellin. The mechanism and regulatory pathway controlling variation in stomatal development in response to environmental signals such as photoreceptors, temperature, and humidity is uncertain. Other problems include determining the genes and pathways involved in stomatal development, ascertaining whether the molecular mechanism of stomatal development differs between monocotyledons and dicotyledons, and understanding how 
intercellular signaling is superimposed and orients the intrinsic polarity. Finally, how environmental signals modulate stomatal development needs to be elucidated. Many questions thus remain to be addressed. In a word, the genetic network for the regulation of stomatal development is too complex and tightly impacted by both intrinsic and external signals. The exact molecular mechanisms underlying the interactions among the various impact factors and environmental signals during stomatal development deserve further investigation.

Acknowledgments. We express our gratitude to the anonymous reviewers for helpful comments to improve the manuscript. This work was supported by the National Key R\&D Program of China (Grant No. 2018YFD0300305-01) and the Open Projects Program of the Key Laboratory of Ministry of Agriculture and Ministry of Education of the People's Republic of China.

\section{REFERENCES}

[1] Abrash, E. B., Bergmann, D. C. (2010): Regional specification of stomatal production by the putative ligand CHALLAH. - Development 13: 447-455.

[2] Acharya, B. R., Jeon, B. W., Zhang, W., Assmann, S. M. (2013): Open Stomata 1 (OST1) is limiting in abscisic acid responses of Arabidopsis guard cells. - New Phytol. 200: 1049-1063.

[3] Arve, L. E., Kruse, O. M. O., Tanino, K. K., Olsen, J. E., Futsæther, C., Torre, S. (2015): ABA regulation and stomatal malfunctioning in Arabidopsis thaliana developed in continuous high air humidity. - Environ. Exp. Bot. 115: 11-19.

[4] Bergmann, D. C., Sack, F. D. (2007): Stomatal development. - Annu. Rev. Plant Biol. 58: 163-181.

[5] Caine, R. S., Chater, C. C., Kamisugi, Y., Cuming, A. C., Beerling, D. J., Gray, J. E., Fleming, A. J. (2016): An ancestral stomatal patterning module revealed in the nonvascular land plant Physcomitrella patens. - Development 143: 3306-3314.

[6] Carvalho, D. R. A., Torre, S., Kraniotis, D., Almeida, D. P. F., Heuvelink, E., Carvalho, S. M. P. (2015): Elevated air movement enhances stomatal sensitivity to abscisic acid in leaves developed at high relative air humidity. - Front. Plant Sci. 6: 11.

[7] Casson, S. A., Hetherington, A. M. (2010): Environmental regulation of stomatal development. - Curr. Op. in Plant Biol. 13: 90-95.

[8] Casson, S. A., Franklin, K. A., Gray, J. E., Grierson, C. S., Whitelam, G. C., Hetherington, A. M. (2009): Phytochrome B and PIF4 regulate stomatal development in response to light quantity. - Curr. Biol. 19: 229-234.

[9] Davies, K. A., Bergmann, D. C. (2014): Functional specialization of stomatal bHLHs through modification of DNA-binding and phospho regulation potential. - Proc. Natl. Acad. Sci. USA.111(43): 15585-15590.

[10] de Marcos, A., Triviño, M., Fenoll, C., Mena, M. (2016): Too many faces for TOO MANY MOUTHS? - New Phytol. 210(3): 779-785.

[11] Delgado, D., Ballesteros, I., Torres-Contreras, J., Mena, M., Fenoll, C. (2012): Dynamic analysis of epidermal cell divisions identifies specific roles for COP10 in Arabidopsis stomatal lineage development. - Planta 236: 447-461.

[12] Doi, M., Shigenaga, A., Emi, T., Kinoshita, T., Shimazaki, K. (2004): A transgene encoding a blue-light receptor, phot1, restores bluelight responses in the Arabidopsis phot1 phot 2 double mutant. - J. Exp. Bot. 55: 517-523.

[13] Du, J., Jiang, H., Sun, X., et al. (2018): Auxin and gibberellins are required for the receptor-like kinase ERECTA regulated hypocotyl elongation in shade avoidance in arabidopsis. - Frontiers in Plant Science 9: 124. 
[14] Engineer, C. B., Ghassemian, M., Anderson, J. C., Engineer, C. B., Ghassemian, M., Anderson, J. C. (2014): Carbonic anhydrases, EPF2 and a novel protease mediate $\mathrm{CO}_{2}$ control of stomatal development. - Nature 513: 246-250.

[15] Engineer, C. B., Hashimoto-Sugimoto, M., Negi, J., Israelsson-Nordström, M., AzoulayShemer, T., Rappel, W. J., Iba, K., Schroeder, J. I. (2016): $\mathrm{CO}_{2}$ sensing and $\mathrm{CO}_{2}$ regulation of stomatal conductance: advances and open questions. - Trends in Plant Science 21(1): 16-30.

[16] Geisler, M., Nadeau, J., Sack, F. D. (2000): Oriented asymmetric divisions that generate the stomatal spacing pattern in Arabidopsis are disrupted by the too many mouths mutation. - Plant Cell 12: 2075-2086.

[17] Gimenez-Ibanez, S., Boter, M., Ortigosa, A., García-Casado, G., Chini, A., Lewsey, M. G., Ecker, J. R., Ntoukakis, V., Solano, R. (2017): JAZ2 controls stomata dynamics during bacterial invasion. - New Phytol. 213: 1378-1392.

[18] Głowacka, K., Kromdijk, J., Kucera, K., Xie, J. Y., Cavanagh, A. P., Leonelli, L., Leakey, ADB., Ort, D. R., Niyogi, K. K., Long, S. P. (2018): Photosystem II Subunit S overexpression increases the efficiency of water use in a field-grown crop. - Nature Communication 9: 868.

[19] Gray, J. E., Holroyd, G. H., Lee, F. M., Bahrami, A. R., Sijmons, P. C., Woodward, F. I., Schuch, W., Hetherington, A. M. (2000): The HIC signalling pathway links $\mathrm{CO}_{2}$ perception to stomatal development. - Nature 408: 713-716.

[20] Han, X., Hu, Y., Zhang, G., Jiang, Y., Chen, X., Yu, D. (2018): Jasmonate negatively regulates stomatal development in Arabidopsis cotyledons. - Plant Physiology 176(4): 2871-2885.

[21] Hara, K., Yokoo, T., Kajita, R., Onishi, T., Yahata, S., Peterson, K. M., Torii, K. U., Kakimoto, T. (2009): Epidermal cell density is auto-regulated via a secretory peptide, EPIDERMAL PATTERNING FACTOR 2 in Arabidopsis leaves. - Plant Cell Physiol. 50: 1019-1031.

[22] Hashimoto-Sugimoto, M., Higaki, T., Yaeno, T., Nagami, A., Irie, M., Fujimi, M., Miyamoto, M., Akita, K., Negi, J., Shirasu, K., Hasezawa, S., Iba, K. (2013): A Munc13like protein in Arabidopsis mediates H+-ATPase translocation that is essential for stomatal responses. - Nat. Commun. 4: 2215.

[23] Hayashi, M., Inoue, S. I., Ueno, Y., Kinoshita, T. (2017): A Raf-like protein kinase BHP mediates blue light-dependent stomatal opening. - Sci. Rep. 7: 45586.

[24] He, J., Zhang, R., Peng, K., Tagliavia, C., Li, S., Xue, S., Hetherington, A. M. (2018): The BIG protein distinguishes the process of $\mathrm{CO}_{2}$-induced stomatal closure from the inhibition of stomatal opening by $\mathrm{CO}_{2}$. - New Phytologist 218(1): 232-241.

[25] He, J. X., Gendron, J. M., Yang, Y., Li, J., Wang, Z. Y. (2002): The GSK3-like kinase BIN2 phosphorylates and destabilizes BZR1, a positive regulator of the brassinosteroid signaling pathway in Arabidopsis. - Proc. Natl. Acad. Sci. USA 99: 10185-10190.

[26] Hedrich, R., Geiger, D. (2017): Biology of SLAC1-type anion channels from nutrient uptake to stomatal closure. - New Phytol. 216: 46-61.

[27] Hirayama, T., Shinozaki, K. (2007): Perception and transduction of abscisic acid signals: Keys to the function of the versatile plant hormone ABA. - Trends Plants Sci. 12: 343351.

[28] Hiyama, A., Takemiya, A., Munemasa, S., et al. (2017): Blue light and $\mathrm{CO}_{2}$ signals converge to regulate light-induced stomatal opening. - Nature Communications 8: 1284.

[29] Hong, D., Jeon, B. W., Kim, S. Y., Hwang, J., Lee, Y. (2016): The ROP2-RIC7 pathway negatively regulates light-induced stomatal opening by inhibiting exocyst subunit Exo70B1 in Arabidopsis. - New Phytol. 209: 624-635.

[30] Horrer, D., Flütsch, S., Pazmino, D., Matthews, J. S., Thalmann, M., Nigro, A., Leonhardt, N., Lawson, T., Santelia, D. (2016): Blue light induces a distinct starch degradation pathway in guard cells for stomatal opening. - Curr. Biol. 26: 1-9. 
[31] Horst, R. J., Fujita, H., Lee, J. S., Rychel, A. L., Garrick, J. M., Kawaguchi, M., Peterson, K. M., Torii, K. U. (2015): Molecular framework of a regulatory circuit initiating twodimensional spatial patterning of stomatal lineage. - PLOS Genetics 11: e1005374.

[32] Hu, H., Boisson-Dernier, A., Israelsson-Nordström, M., Böhmer, M., Xue, S., Ries, A., Godoski, J., Kuhn, J. M., Schroeder, J. I. (2010): Carbonic anhydrases are upstream regulators of $\mathrm{CO}_{2}$-controlled stomatal movements in guard cells. - Nature Cell Biol. 12: $87-93$.

[33] Hu, H., Rappel, W. J., Occhipinti, R., Ries, A., Böhmer, M., You, L., Xiao, C. L., Engineer, C. B., Boron, W. F., Schroeder, J. I. (2015): Distinct cellular locations of carbonic anhy-drases mediate $\mathrm{CO}_{2}$ control of stomatal movements. - Plant Physiology 169: 1168-1178.

[34] Hunt, L., Gray, J. E. (2009): The signaling peptide EPF2 controls asymmetric cell divisions during stomatal development. - Curr. Biol. 19: 864-869.

[35] Hunt, L., Bailey, K. J., Gray, J. E. (2010): The signaling peptide EPFL9 is a positive regulator of stomatal development. - New Phytol. 186: 609-614.

[36] Jakobson, L., Vaahtera, L., Tõldsepp, K., Nuhkat, M., Wang, C., Wang, Y. S., et al. (2016): Natural variation in Arabidopsis Cvi-0 accession reveals an important role of MPK12 in guard cell $\mathrm{CO}_{2}$ signaling. - PLoS Biol 14(12): e2000322.

[37] Jalakas, P., Huang, Y., Yeh, Y., Zimmerli, L., Merilo, E., Kollist, H., Brosché, M. (2017): The role of ENHANCED RESPONSES TO ABA1 (ERA1) in Arabidopsis stomatal responses is beyond ABA signaling. - Plant Physiology 174(2): 665-671.

[38] Jalakas, P., Merilo, E., Kollist, H., Brosché, M. (2018): ABA-mediated regulation of stomatal density is OST1-independent. - Plant Direct. 2: 1-7.

[39] Kanaoka, M. M., Pillitteri, L. J., Fujii, H., Yoshida, Y., Bogenschutz, N. L., Takabayashi, J., Zhu, J. K., Torii, K. U. (2008): SCREAM/ICE1 and SCREAM2 specify three cell-state transitional steps leading to Arabidopsis stomatal differentiation. - Plant Cell 20: 17751785 .

[40] Kim, T. W., Michniewicz, M., Bergmann, D. C., Wang, Z. Y. (2012): Brassinosteroid regulates stomatal development by GSK3-mediated inhibition of a MAPK pathway. Nature 482: 419-422.

[41] Lahr, E. C., Schade, G. W., Crossett, C. C., Watson, M. R. (2015): Photosynthesis and isoprene emission from trees along an urban-rural gradient in Texas. - Glob Chang Biol. 21: 4221-4236.

[42] Lampard, G. R., Lukowitz, W., Ellis, B. E., Bergmann, D. C. (2009): Novel and expanded roles for MAPK signaling in Arabidopsis stomatal cell fate revealed by cell type-specific manipulations. - Plant Cell 21: 3506-3517.

[43] Lau, O. S., Song, Z. J., Zhou, Z. M., Davies, K. A., Chang, J., Yang, X., Wang, S. Q., Lucyshyn, D., Tay, I. H. Z., Wigge, P. A., Bergmann, D. C. (2018): Direct control of SPEECHLESS by PIF4 in the high-temperature response of stomatal development. Current Biology 28(8): 1273-1280.

[44] Lee, E., Lucas, J. R., Goodrich, J., Sack, F. D. (2014): Arabidopsis guard cell integrity involves the epigenetic stabilization of the FLP and fama transcription factor genes. - The Plant Journal 78: 566-577.

[45] Lee, J. H., Park, C. M. (2017): Light inhibits COP1-mediated degradation of ICE transcription factors to induce stomatal development in Arabidopsis. - Plant Cell 29: 2817-2830.

[46] Lee, J. S., Hnilova, M., Maes, M., Lin, Y. C. L., Putarjunan, A., Han, S. K., Avila, J., Torii, K. U. (2015): Competitive binding of antagonistic peptides fine-tunes stomatal patterning. - Nature 522: 439-443.

[47] Li, K., Yang, F. B., Zhang, G. Z., Song, S. F., Li, Y., Ren, D. T., Miao, Y. C., Song, C. P. (2017): AIK1, a mitogen-activated protein kinase, modulates abscisic acid responses through the MKK5-MPK6 kinase cascade. - Plant Physiology 173: 1391-1408. 
[48] Liu, L. J., Zhang, Y. C., Li, Q. H., Sang, Y., Mao, J., Lian, H. L., Wang, L., Yang, H. Q. (2008): COP1-mediated ubiquitination of CONSTANS is implicated in cryptochrome regulation of flowering in Arabidopsis. - Plant Cell 20: 292-306.

[49] Lv, S., Zhang, Y., Li, C., Liu, Z., Yang, N., Pan, L., Wu, J., Wang, J., Yang, J., Lv, Y., Zhang, Y., Jiang, W., She, X., Wang, G. (2018): Strigolactone-triggered stomatal closure requires hydrogen peroxide synthesis and nitric oxide production in an abscisic acid-independent manner. - New Phytol. 217: 290-304.

[50] MacAlister, C. A., Ohashi-Ito, K., Bergmann, D. C. (2007): Transcription factor control of asymmetric cell divisions that establish the stomatal lineage. - Nature 445: 537-540.

[51] Mahoney, A. K., Anderson, E. M., Bakker, R. A., Williams, A. F., Flood, J. J., Sullivan, K. C., Pillitteri, L. J. (2016): Functional analysis of the Arabidopsis thaliana MUTE promoter reveals a regulatory region sufficient for stomatal-lineage expression. - Planta 243(4): 987-998.

[52] Matos, J. L., Lau, O. S., Hachez, C., Cruz-Ramírez, A., Scheres, B., Bergmann, D. C. (2014): Irreversible fate commitment in Arabidopsis stomatal lineage requires a FAMA and RETINOBLASTOMA-RELATED module. - elife 3: e03271.

[53] Meng, L. S., Li, C., Xu, M. K., Sun, X. D., Wan, W., Gao, X. Y., Zhang, J. L., Chen, K. M. (2018): Arabidopsis ANGUSTIFOLIA3 (AN3) is associated with the promoter of CONSTITUTIVE PHOTOMORPHOGENICI (COP1) to regulate light-mediated stomatal development. - Plant Cell Environ. https://doi.org/10.1111/pce.13212.

[54] Miura, K., Okamoto, H., Okuma, E., Shiba, H., Kamada, H., Hasegawa, P. M., Murata, Y. (2013): SIZ1 deficiency causes reduced stomatal aperture and enhanced drought tolerance via controlling salicylic acid-induced accumulation of reactive oxygen species in Arabidopsis. - Plant J. 73: 91-104.

[55] Mustilli, A. C., Merlot, S., Vavasseur, A., Fenzi, F., Giraudat, J. (2002): Arabidopsis OST1 protein kinase mediates the regulation of stomatal aperture by abscisic acid and acts upstream of reactive oxygen species production. - Plant Cell 14: 3089-3099.

[56] Ni, D. A. (2012): Role of vacuolar invertase in regulating Arabidopsis stomatal opening. - Acta Physiologiae Plantarum 34(6): 2449-2452.

[57] Ohashi-Ito, K., Bergmann, D. C. (2006): Arabidopsis FAMA controls the final proliferation/differentiation switch during stomatal development. - Plant Cell 18: 24932505.

[58] Park, S. Y., Fung, P., Nishimura, N., Jensen, D. R., Fujii, H., Zhao, Y., Lumba, S., Santiago, J., Rodrigues, A., Chow, T. F., et al. (2009): Abscisic acid inhibits type 2C protein phosphatases via the PYR/PYL family of START proteins. - Science 324: 10681071.

[59] Pei, Z. M., Kuchitsu, K., Ward, J. M., Schwarz, M., Schroeder, J. I. (1997): Differential abscisic acid regulation of guard cell slow anion channels in Arabidopsis wild-type and abil and abi2 mutants. - Plant Cell 9(3): 409-423.

[60] Piisilä, M., Keceli, M. A., Brader, G., Jakobson, L., Joesaar, I., Sipari, N., Kollist, H., Palva, E. T., Kariola, T. (2015): The F-box protein MAX2 contributes to resistance to bacterial phytopathogens in Arabidopsis thaliana. - BMC Plant Biology 15: 53.

[61] Pillitteri, L. J., Sloan, D. B., Bogenschutz, N. L., Torii, K. U. (2007): Termination of asymmetric cell division and differentiation of stomata. - Nature 445: 501-505.

[62] Saibo, N. J., Vriezen, W. H., Beemster, G. T., Van, D. Straeten, D. (2003): Growth and stomata development of Arabidopsis hypocotyls are controlled by gibberellins and modulated by ethylene and auxins. - The Plant Journal 33: 989-1000.

[63] Serna, L., Fenoll, C. (2000): Stomatal development in Arabidopsis: how to make a functional pattern. - Trends in Plant Science 5: 458-460.

[64] Shang, Y., Dai, C., Lee, M. M., Kwak, J. M., Nam, K. H. (2016): BRI1-associated receptor Kinase 1 regulates guard cell ABA signaling mediated by open stomata 1 in Arabidopsis. - Mol. Plant. 9: 447-460. 
[65] Sugano, S. S., Shimada, T., Imai, Y., Okawa, K., Tamai, A., Mori, M., Hara-Nishimura, I. (2010): Stomagen positively regulates stomatal density in Arabidopsis. - Nature 463: 241-244.

[66] Takemiya, A., Shimazaki, K. (2016): Arabidopsis phot1 and phot2 phosphorylate BLUS1 kinase with different efficiencies in stomatal opening. - J. Plant Res. 129(2): 167-174.

[67] Tanaka, Y., Nose, T., Jikumaru, Y., Kamiya, Y. (2013): ABA inhibits entry into stomatal lineage development in Arabidopsis leaves. - Plant J. 74(3): 448-457.

[68] Tian, W., Hou, C. C., Ren, Z. J., Pan, Y. J., Jia, J. J., Zhang, H. W., Bai, F. L., Zhang, P., Zhu, H. F., He, Y. K., Luo, S. L., Li, L. G., Luan, S. (2015): A molecular pathway for $\mathrm{CO}_{2}$ response in Arabidopsis guard cells. - Nat. Commun. 6: 6057.

[69] Vahisalu, T., Kollist, H., Wang, Y. F., Nishimura, N., Chan, W. Y., Valerio, G., Lamminmäki, A., Brosché, M., Moldau, H., Desikan, R., Schroeder, J. I., Kangasjärvi, J. (2008): SLAC1 is required for plant guard cell S-type anion channel function in stomatal signalling. - Nature 52(7186): 487-491.

[70] Vatén, A., Soyars, C. L., Tarr, P. T., Nimchuk, Z. L., Bergmann, D. C. (2018): Modulation of asymmetric division diversity through Cytokinin and SPEECHLESS regulatory interactions in the Arabidopsis stomatal lineage. - Developmental Cell 47: 114.

[71] Von, G. U., Berger, D., Altmann, T. (2002): The subtilisin-like serine protease SDD1 mediates cell-to-cell signaling during Arabidopsis stomatal development. - The Plant Cell 14: 1527-1539.

[72] Yan, J., Zhang, C., Gu, M., Bai, Z., Zhang, W., Qi, T., Cheng, Z., Peng, W., Luo, H., Nan, F., et al. (2009): The Arabidopsis CORONATINE INSENSITIVE1 protein is a jasmonate receptor. - Plant Cell 21: 2220-2236.

[73] Zhang, H., Pan, C., Gu, S., Ma, Q., Zhang, Y., Li, X., Shi, K. (2018): Stomatal movements are involved in elevated $\mathrm{CO}_{2}$-mitigated high temperature stress in tomato. Physiol Plantarum. DOI: 10.1111/ppl.12752.

[74] Zhu, J. Y., Sae-Seaw, J., Wang, Z. Y. (2013): Brassinosteroid signalling. - Development 140: $1615-1620$. 